\title{
Genetic evidence for cryptic speciation in the freshwater shrimp genus Atyaephyra de Brito Capello (Crustacea, Decapoda, Atyidae)
}

\author{
JOSÉ E. GARCÍA MUÑOZ ${ }^{1,2}$, ANTONIO RODRÍGUEZ1 , J. ENRIQUE GARCÍA RASO² \& \\ JOSÉ A. CUESTA ${ }^{1}$

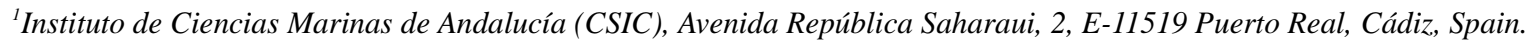 \\ E-mail:alexoriones@hotmail.com, antonio.rodriguez@icman.csic.es, jose.cuesta@icman.csic.es \\ ${ }^{2}$ Departamento de Biología Animal, Facultad de Ciencias, Universidad de Málaga. Campus de Teatinos s/n, E-29071 Málaga, Spain. \\ E-mail: garciaraso@uma.es
}

\begin{abstract}
The species Atyaephyra desmarestii (Millet, 1831) has a wide geographic distribution in freshwater habitats, rivers and lakes, spanning from North Africa to the Middle East, a large part of Europe and some Mediterranean islands. This wide distribution, together with the disjunct nature of freshwater populations, makes A. desmarestii a candidate taxon to undergo processes of cryptic speciation. To test this assumption, in the present study two mitochondrial genes (16S and COI) were used to examine the diversity between selected populations across the distribution range of this species. The data support three clearly distinguishable groups of haplotypes. The largest one includes the majority of the west European populations and the North African ones, belonging to Atyaephyra desmarestii desmarestii. Within this group the genetic composition found for the Portuguese specimens does not support the validity of Atyaephyra rosiana de Brito Capello, 1867 as a different species, and is therefore here proposed to represent a synonym of Atyaephyra desmarestii. The second European group includes two Greek populations which must be considered as a different species and are tentatively identified as Atyaephyra stankoi (Karaman, 1972) according to geographic distribution. This species-level distinction is supported by high genetic differences, although morphological differentiation is not clear at present. The third group comprises only one sequence from Iraq whose value of genetic variability for $16 \mathrm{~S}$ could support $A$. mesopotamica Al-Adhub (or A. orientalis Bouvier) as a valid species. Unfortunately, there are no COI sequences available for this specimen that could be used to confirm its status.
\end{abstract}

Key words: Cryptic species, Atyaephyra desmarestii complex, Atyidae, 16S, COI

\section{Introduction}

The monotypic genus Atyaephyra de Brito Capello, 1867 is represented by a single widespread species, Atyaephyra desmarestii (Millet, 1831), recorded in freshwater habitats from the Mediterranean Basin and the Middle East (D’Udekem D’Acoz 1999 and references therein). The current distribution includes North Africa (Morocco, Algeria, Tunisia, but no reports from Libya nor Egypt) the Middle East (Syria, Israel, Iraq, and Iran), the European mainland (Portugal, Spain, France, Italy, Albania, Croatia, Greece and Turkey), and islands (Corsica, Sardinia, Sicily). Furthermore it has been introduced to Belgium, The Netherlands, Denmark and Germany from France; and there is a non-confirmed citation from Madeira Island. Across its distribution, four subspecies have been distinguished: A. d. desmarestii (Millet, 1831), A. d. orientalis Bouvier, 1913, A. d. stankoi Karaman, 1972, and A. d. mesopotamica Al-Adhub, 1987, and recently the species A. rosiana de Brito Capello, 1867 has been resurrected as valid by Anastasiadou et al. (2008).

Atyaephyra desmarestii has a confused taxonomic history: it was described by Millet in 1831 as Hippolyte desmarestii from specimens collected in the rivers of the Maine and Loire area (Mayenne, Sarthe, Loir, Thouet and Layon), France. This description was brief with two figures without many details. Milne Edwards 